\title{
An Examination of the Nature and Correlates of Ethnic Harassment Experiences in Multiple Contexts
}

\author{
Kimberly T. Schneider, Robert T. Hitlan, and Phanikiran Radhakrishnan \\ University of Texas at El Paso
}

\begin{abstract}
The authors examined the nature and correlates of ethnic harassment experiences in 4 predominantly Hispanic samples of working men and women $(N=575)$ using a newly developed scale. Confirmatory factor analyses supported a 2-factor structure for the Ethnic Harassment Experiences scale (i.e., verbal ethnic harassment and exclusion due to ethnicity). Most experiences of ethnic harassment in the workplace during the previous 24 months included verbal ethnic harassment (i.e., ethnic slurs, derogatory ethnic comments, or ethnic jokes). It was also found that participants who experienced verbal ethnic harassment and exclusion reported negative correlates that could not be attributed to affective disposition. For some correlates, those who experienced low levels of verbal harassment and high levels of exclusion were more negatively affected than others, perhaps as a result of the attributional ambiguity of the situation.
\end{abstract}

This article focuses on an important type of workplace harassment that is of growing concern to contemporary institutions, namely, harassment due to one's race or ethnicity. As organizations and institutions become more ethnically diverse, racial or ethnic harassment may become more frequent and may result in multiple negative outcomes. Although previous research on racialethnic discrimination and harassment has failed to differentiate between the two concepts, we differentiate ethnic harassment from discrimination. We conceptualize ethnic harassment ${ }^{1}$ as threatening verbal conduct or exclusionary behavior that has an ethnic component and is directed at a target because of his or her ethnicity. The construct is composed of behaviors that may be encountered on a daily basis and may contribute to a hostile environment, particularly for ethnic minorities. Ethnic discrimination is defined as unequal job treatment or lack of positive opportunities because of one's race-ethnicity (Radhakrishnan \& Hitlan, 1998). Like S. A. James, LaCroix, Kleinbaum, and Strogatz (1984) and Cervantes (1992), we conceptualize discriminatory behaviors as structural or contextual variables that impede job opportunities or earning potential. Under this definition, discrimination is viewed as an institutional or structural variable, whereas ethnic harassment is similar to hostile environment sexual harassment. We view harassment and discrimination as two related constructs

Kimberly T. Schneider, Robert T. Hitlan, and Phanikiran Radhakrishnan, Department of Psychology, University of Texas at El Paso.

The University of Texas at El Paso Research Institute provided funds to assist in the data collection for Samples 1,2, and 4. Results based on Samples 3 and 4 were presented at the 1998 conference of the Society for Industrial and Organizational Psychology in Dallas, Texas. We thank Penny Flores, Sandra Goldsmith, Julie Henry, Chasey Hunker, Rafael Ramos, Sabrina Campbell, and Pam Ziegler for their assistance in data collection and data coding.

Correspondence concerning this article should be addressed to Kimberly T. Schneider, Department of Psychology, University of Texas at El Paso, El Paso, Texas 79968. Electronic mail may he sent to kschneid@mail. utep.edu. that comprise a behavioral family of ethnically relevant workplace behaviors.

We propose that ethnic harassment in the workplace is a stressor composed of two factors: slurs or derogatory comments about a target's ethnic group and exclusion of the target from work-related or social interactions as a result of his or her ethnicity. The psychological stress caused by ethnic harassment may be severe for employees, and organizations may sacrifice productivity if employee complaints concerning ethnic harassment are not taken seriously (Harrick \& Sullivan, 1995).

The verbal harassment and exclusionary behaviors that, we propose, constitute ethnic harassment correspond to anecdotal evidence of the types of experiences reported by ethnic minorities. In predominantly White work settings, members of ethnic minority groups are sometimes deprived of important job information, may not be told about certain events, or may be given the wrong date or time of an event (E. M. J. Smith, 1985). This exclusion is similar to aversive racism (Gaertner \& Dovidio, 1986), which is defined by subtle, indirect, and covert discriminatory behaviors. In contrast, verbal ethnic harassment behaviors may allow a harasser to enact overt hostility toward those of other ethnicities. This is similar to Feagin's (1991) discussion of the relatively common occurrence of racial verbal epithets during White-Black casual street encounters.

In the present study, we collected data from four samples of working men and women. The two purposes of the study were to examine the structure of a recently developed scale, the Ethnic Harassment Experiences scale (EHE), and to examine the relations between ethnic harassment and its correlates. We included diverse samples, composed predominantly of Hispanics, from different organizational contexts, along with a wide range of job-related,

\footnotetext{
${ }^{1}$ We have chosen to focus on the consequences of ethnic harassment given the populations available in this study and the nature of the harassment measure, although we suspect that the consequences of racial harassment are similar to those of ethnic harassment.
} 
psychological, and health-related measures selected to assess the nature and correlates of ethnic harassment. Because most studies of discrimination compare African Americans and Anglos, we view our comparisons between Hispanics and Anglos as an important extension.

\section{Research on Discrimination and Harassment}

Previous research has failed to differentiate between racialethnic harassment and racial-ethnic discrimination. It has relied on indicators that assess both harassment and discrimination experiences (e.g., Thompson, 1996) or has used measures that assess both ethnic and gender discrimination (e.g., Gutierres, Saenz, \& Green, 1994; Pak, Dion, \& Dion, 1991). Although the measures used in these studies have questionable psychometric properties, the usefulness of their findings should not be underestimated. Such studies specify the kinds of outcomes one might expect from ethnic harassment and also suggest how harassment and discrimination may be related (Szymanski, 1976).

Because of the lack of attention paid to ethnic harassment at work, and because we view ethnic harassment and discrimination as related constructs, we relied on studies of discrimination in nonwork settings and sexual harassment in the workplace (as described subsequently) to derive hypotheses about the expected relationships between ethnic harassment and its correlates. For example, multiple studies have demonstrated that discrimination is related to stress. Chinese students' experiences of discrimination have been shown to be related to higher levels of stress, particularly among women (Pak et al., 1991). Also, African Americans who experience incidents of racism have been shown to report more symptoms of intrusion and avoidance (Thompson, 1996), reactions that are similar in nature to posttraumatic stress.

Several studies also report that discrimination is related to negative physiological indexes. Krieger and Sidney (1996) found that African Americans who reported that they had been made to feel inferior on the basis of race had higher blood pressure, measured during a subsequent medical examination, than participants who did not report such experiences. Similarly, Mexican Americans' reports of discrimination experiences have been shown to predict blood pressure levels, in addition to self-reported illness (K. James, Lovato, \& Khoo, 1994). Minority employees who experience higher levels of workplace prejudice and discrimination have been shown to report more psychosomatic health problems than those who did not have such experiences (K. James, 1994).

Gutierres et al. (1994) found that, regardless of ethnicity, participants who perceived high levels of discrimination against women and minorities in a university reported greater job stress than those who perceived low levels of discrimination. They also reported an interesting pattern of relationships among ethnicity, discrimination, and health correlates. Among White participants, perceived discrimination was not related to health; however, among Hispanic participants who reported low levels of social support, perceived discrimination influenced self-reported health conditions. Specifically, Hispanics who perceived high levels of workplace discrimination reported more health problems than those who perceived low levels of discrimination.

Because we did not find many psychometrically sound empirical studies involving discrimination experiences and job-related correlates, we examined research on the links between job-related and psychological well-being correlates and both sexual harassment and ethnic prejudice to develop some of our hypotheses. We view ethnic harassment as a workplace stressor similar to other social stressors in the workplace (e.g., sexual harassment) and propose that the job-related correlates of ethnic harassment may be similar to those of sexual harassment, also conceptualized as a workplace social stressor (Fitzgerald, Hulin, \& Drasgow, 1995). Similar to job stress, sexual harassment has extremely detrimental effects on job-related, psychological, and health-related correlates (Fitzgerald, Drasgow, Hulin, Gelfand, \& Magley, 1997; Schneider, Swan, \& Fitzgerald, 1997; see also Szymanski, 1976), effects that cannot be explained by dispositional influences or general job stress. Using this research as a framework, we then referred to research on stigmatized individuals to link ethnic harassment experiences with job attitudes, job behaviors, and psychological well-being.

\section{Proposed Correlates of Ethnic Harassment and Hypothesized Interactions}

We used Crocker, Major, and Steele's (1998) research on stigmatized individuals (i.e., those devalued by others because of a particular salient attribute) to develop specific hypotheses linking ethnic harassment to negative job correlates. Crocker et al. (1998) proposed a theoretical model linking discrimination experiences to threats to targets' self-worth and esteem. Research on social stigma and stereotype threat (Crocker \& Major, 1994; Steele \& Aronson, 1995) suggests that targets who experience stigma in a valued domain (e.g., academic achievement) may protect their sense of identity by disengáging from the task. We propose that, similar to stigmatized individuals, targets of ethnic harassment may respond to their experience by disengaging from their work situation. That is, they may withdraw from work in an attempt to distance themselves physically (e.g., through absenteeism or tardiness) or psychologically (e.g., through drinking alcohol or using drugs) from the harassing situation. Therefore, we hypothesized that targets of ethnic harassment would report negative job attitudes and job behaviors as a reflection of their negative experiences with coworkers or supervisors.

Next, we referred to Hobfoll's (1991) model of traumatic experiences and the empirical evidence of links between discrimination and negative psychological well-being (Pak et al., 1991; Thompson, 1996) to develop our hypothesis that ethnic harassment experiences would be related to symptoms of anxiety, depression, and lowered life satisfaction. Hobfoll (1991) argued that individuals who experience trauma develop psychosomatic symptoms (e.g., anxiety and depression) because of the unexpectedness of the traumatic event and because they believe that the event was not under their control. We hypothesized such a link between ethnic harassment and negative psychological well-being because ethnic harassment represents a threatening event in the workplace. Finally, on the basis of empirical evidence that racial discrimination is related to psychosomatic complaints and elevated blood pressure (K. James, 1994; Krieger \& Sidney, 1996), we expected a relation between ethnic harassment experiences and negative physical health symptoms.

We also hypothesized that targets of multiple types of ethnic harassment would report extremely negative correlates of the ex- 
perience. Job stress research indicates that employees often do not experience isolated stressors and that the effects of multiple stressors may significantly affect employees (Hanisch, 1996; Kahn \& Byosiere, 1992). A. Smith and Stewart (1983) argued that ethnic minority women who experience multiple types of harassment experience more negative outcomes than those subjected to only gender or ethnic harassment (see also K. James \& Khoo, 1991). Similarly, we expected that experiencing multiple types of ethnic harassment (i.e., both verbal harassment and exclusion) would exacerbate the relation between ethnic harassment and its correlates.

On the basis of the work of Gutierres et al. (1994) and Ruggiero and Major (1998), we explored an interaction of harassment experiences with ethnicity. Ruggiero and Major (1998) found that members of low-status groups (e.g., women and Blacks) were less likely than members of high-status groups (e.g., men and Whites) to attribute negative outcomes to discrimination, indicating that, for lower status groups, labeling their experiences as discrimination may be psychologically costly. However, in their examination of outcomes, Gutierres et al. (1994) found that although Whites and Hispanics both reported perceiving similar levels of discrimination, only the health of Hispanics was related to these perceptions. It should be noted that the Gutierres et al. study confounded personal experiences of discrimination with perceptions of discrimination against others. On the basis of these conflicting results related to possible differential effects of harassment experiences, we explored an interaction between harassment and ethnicity.

Because we relied on self-report measures, and the validity of such measures may be affected by factors such as negative affectivity (see Watson \& Pennebaker, 1989), we removed the effects of participants' affective disposition from the relationships between ethnic harassment and its correlates. We expected that our hypothesized relationships would exist after removal of variance due to respondents' general predisposition to respond in a negative manner, indicating that these relationships could not be explained by employees' tendency to complain about innocuous events in the workplace.

\section{Method}

\section{Participants}

Four samples participated in the study. Sample 1 consisted of 127 working students enrolled in a predominantly Hispanic southwestern university. All participants received class credit for taking part, and all were sampled from either the introductory psychology participant pool or upperlevel courses in the business department. The majority of the participants ( $81 \%$ ) were Hispanic; $15.1 \%$ were Anglo, $2.4 \%$ were African American, and $1.6 \%$ were Asian or Indian. Because all four of our samples were primarily Hispanic with reasonable percentages of Anglos and little representation of other ethnic groups, we focus on data from our Hispanic and Anglo participants. In Sample 1, the subset of Hispanic and Anglo participants $(n=121)$ comprised 63 women and 58 men.

Sample 2 was composed of 50 university students enrolled in an upperlevel psychology course at the same university as in Sample 1. All participants were given class credit for their participation. The majority of participants (76\%) werc Hispanic; $16 \%$ were Anglo, and $8 \%$ were Asian American or African American. No students in this sample were in Sample 1. The subset of Hispanic and Anglo participants $(n=46)$ comprised 18 men and 28 women.

Sample 3 consisted of employees of a large municipal school district located in the Southwest. The majority of employees worked in the district's administrative office as either school administrators or paraprofessionals $(63 \%)$; the rest were school teachers working at an elementary, middle, or high school campus. The campus sites selected for inclusion in the study were drawn from a random sample of elementary, middle, and high schools. The participants were also randomly chosen from each site on the basis of a roster of all employees at the site. The majority of the participants were Hispanic (50.4\%); $42 \%$ were Anglo, $3.4 \%$ were African American, $1.7 \%$ were Asian American, and $1.7 \%$ were American Indian (one person did not indicate his or her ethnicity). The final sample represented approximately $40 \%$ of those chosen to participate, and the subset of Hispanic and Anglo participants $(n=110)$ comprised 81 women and 29 men.

In Sample 4, 1,500.graduate students at a large southwestern university were mailed a paper-and-pencil questionnaire; 361 returned the questionnaire (response rate: $24 \%$ ). The respondents who retumed their surveys did not differ by ethnicity. Previous campus studies of this kind (Hurtardo, 1992; Reid \& Radhakrishnan, 1998) have yielded response rates of $20 \%$ or slightly higher. A slight majority of the participants were Hispanic (48.1\%); $41.4 \%$ were Anglo, $3.6 \%$ were Asian American, $3.6 \%$ were biracial, $1.8 \%$ were East Indian, and $1.5 \%$ were African American. The subset of Hispanic and Anglo students $(n=295)$ comprised 194 women and 101 men.

\section{Measures and Procedure}

All samples completed a paper-and-pencil survey assessing their workplace or campus harassment experiences; instances in which there were differences in questionnaires administered to a sample are described subsequently. Surveys were administered to Samples 1 and 2 in small-group sessions scheduled in the laboratory. Members of Sample 3 completed the survey in small-group sessions at their work sites either before or after work hours. We sent letters to the offices of those employees who were chosen to participate informing them of the nature of the survey and the time and location of the survey administration. The survey was described to participants as a workplace experiences questionnaire to avoid priming ideas regarding harassment. Participants were also informed, in the initial letter and during the survey administration, of their rights as research participants.

Sample 4, the graduate student sample, received the survey via mail during the second semester of the academic year. Participants were given postage-paid envelopes to return their surveys to the researchers. They were informed, in a cover letter that accompanied the survey, of their rights as participants. To encourage participation, we telephoned all students 2 weeks after the initial mailing of surveys either to thank them for taking part (if they indicated they had retumed the survey) or to remind them to return their survey.

Ethnic harassment experiences. The EHE was developed in a previous study from a content analysis of the comments of working students who described situations in which their ethnicity had caused conflict at work (Schneider, 1997). In the scale development stage, participants completed paper-and-pencil questionnaires administered in small groups and were asked to write about their experiences of interethnic conflict. A content analysis of their responses revealed seven common themes that were developed into items. Subsequent exploratory factor analyses of students' responses to these seven items indicated two factors that we defined as being excluded from work-related interactions because of ethnicity and being the target of verbal ethnic harassment. The response scale of the EHE was structured after the Sexual Experiences Questionnaire (Fitzgerald et al., 1988), such that potentially ethnically harassing behaviors were listed and respondents indicated how often they had experienced each behavior at their organization within the previous 24 months.

Participants in all four samples completed the EHE. Samples 1 and 3 completed the EHE by referring to experiences at their organization during the previous 24 months, whereas Samples 2 and 4 referred to their expe- 
riences on campus. Participants indicated, on a 5-point response scale, how frequently they experienced each behavior (e.g., never to almost always). Although Samples 1 and 2 completed only the EHE, Samples 3 and 4 also responded to measures assessing job-related attitudes or behaviors, psychological well-being, and health-related status. The EHE appeared after these measures. We used some common and some different jobrelated and psychological well-being measures in Samples 3 and 4 to maximize the type of information we obtained from the two samples while keeping the surveys at a reasonable length. In Sample 3, male and female versions of the survey were developed that were equivalent with the exception of an additional posttraumatic stress scale administered to female but not male participants. ${ }^{2}$ Correlations among all seale variables within each sample are shown in Table 1, along with reliability indexes.

Job-related attitudes and behaviors. We measured job-related attitudes of the graduate student sample and job behaviors of both the school district and graduate student samples. Job attitude measures included the Satisfaction With Coworkers, Satisfaction With Supervision, and Satisfaction With Work subscales of the Job Descriptive Index (Roznowski, 1989: P. C. Smith, Kendall, \& Hulin, 1969).

Job behaviors were assessed with a measure of work withdrawal constructed by Hanisch and Hulin (1991). This instrument was used in both samples to assess levels of absenteeism, tardiness, and other unfavorable job behaviors, such as stealing from the organization. The full 21 -item version of the scale was included in the school district sample, whereas a shorter, 11-item version was used in the graduate student survey. In both samples, respondents indicated how frequently they engaged in each behavior using a 7-point frequency scale. In addition, the graduate student sample completed a measure of job withdrawal defined as intent to leave the university. This was measured by three items adapted from Hanisch and Hulin (1991) that assessed participants' likelihood of quitting, perceptions of the desirability of quitting, and frequency of thoughts of quitting the university. A 5-point response scale was used.

Psychological well-being and health measures. Life satisfaction was assessed in both Samples 3 and 4 via the five-item Satisfaction with Life Scale (Diener, Emmons, Larsen, \& Griffin, 1985), in which respondents indicated the extent to which they were generally satisfied with life using a 7-point Likert scale. Mental health was assessed in Sample 3 with 14 anxiety and depression items from the Mental Health Index; respondents indicated how they had felt during the previous month using a 6-point frequency scale (Veit \& Ware, 1983). A 10-item measure of symptoms of posttraumatic stress disorder (Saunders, Arata, \& Kilpatrick, 1990) was also administered to female participants in Sample 3 to assess stress-related symptoms such as "feeling afraid in open spaces."

The graduate student sample also completed scales assessing health conditions and health satisfaction. Health symptoms were assessed with the Health Conditions Index, adapted from the Cornell Medical Checklist (Brodman, Erdman, Lorge, \& Wolff, 1949). Participants used a yes-no response format to indicate the presence or absence of 12 health symptoms such as severe headaches and feelings of exhaustion for no good reason. Health satisfaction was measured via the nine-item Health Satisfaction subscale of the Retirement Descriptive Index (P. C. Smith et al., 1969). Participants used the response format of the Job Descriptive Index to indicate their perceptions of their health (e.g., excellent, poor, must be careful what I do).

Affective disposition. In Samples 3 and 4, we included a measure of affective disposition for use as a control variable in examining the relationships between ethnic harassment and its correlates. Affective disposition was assessed with a revised version of Weitz's (1952) Satisfaction

\footnotetext{
${ }^{2}$ In Sample 3, we developed male and female versions of the survey because the organization suggested that male employees might react negatively to the posttraumatic stress scale. Men were not given the posttraumatic stress scale or mental health scale.
} 
with Neutral Objects Questionnaire (see Judge, 1990). We used 13 items that assessed respondents' satisfaction with neutral items (e.g., size of refrigerators and color of stop signs). Respondents indicated, on a 3-point response scale, whether they felt satisfied, neutral, or dissatisfied in regard to each object.

\section{Results}

We first examine the structure of the EHE using confirmatory factor analyses and then present an overview of the experiences of ethnic harassment reported by targets in each sample. Finally, using Samples 3 and 4, we examine the correlates of ethnic harassment. We had no a priori reason to expect differences across the four samples in terms of either the nature or frequencies of harassment experiences or the correlates of ethnic harassment, nor did we expect gender differences. The samples were fairly similar in the sense that both the sample participants and their workplace or campus environments were predominantly Hispanic, and Samples 3 and 4 consisted of people interacting in an educational context (i.e., students, teachers, or school administrators).

\section{Confirmatory Factor Analysis of the EHE}

To examine the structure of the EHE, we performed a confirmatory factor analysis using maximum likelihood estimation. First, because there were relatively large numbers of Anglo $(n=$ 208) and Hispanic $(n=360)$ participants, and we were not confident that the same factor structure and factor intercorrelations existed for the two groups, we performed a multiple-group confirmatory factor analysis to assess construct equivalence (Drasgow \& Kanfer, 1985; Jöreskog \& Sörbom, 1996).

Using LISREL 8.14 (Jöreskog \& Sörbom, 1996), we began by testing the least restrictive model across the two ethnic groups, one that specified an equal number of factors for the two groups. We specified two factors to describe the structure and dimensionality of ethnic harassment experiences. We hypothesized that four items would represent the verbal harassment factor (i.e., making derogatory comments about one's ethnicity, telling jokes about one's ethnic group, using ethnic slurs, and making racist comments) and allowed the remaining three items to load on the exclusion factor (i.e., exclusion from social interactions, failure to obtain jobrelated information because of ethnicity, and giving up ethnic identity to get along at work). Fit indexes and ratios of chi-square values to degrees of freedom are shown in Tabie 2; all indicated a good fit.
The next step of the multisample analysis involved specifying not only an equal number of factors but equal loadings of the EHE items onto their respective factors across the two groups (i.e., invariant $\Lambda_{x}$ matrices). Indexes of fit (see Table 2) were acceptable, indicating that the factor loadings were equivalent across ethnic groups. We next tested an even more restrictive model specifying an equal number of factors, equal factor loadings, and equal factor intercorrelations (i.e., invariant $\phi$ matrices) across the two groups. As shown in Table 2, the added restriction of an equal factor intercorrelation between the two ethnic groups did not significantly deteriorate the fit of the model. Finally, we tested the most restrictive model, one specifying an equal number of factors, equal factor loadings, equal factor intercorrelations, and equal error variances (i.e., invariant $\Theta_{\delta}$ matrices). With the addition of the constraint of equal error variances for the two ethnic groups, the model deteriorated (see Table 2).

Although we added this last constraint of equal error variances, we should note that some authors suggest that it is not necessary to test group equality of variances because group measurement errors may differ even if the measurement model is equivalent in the groups (MacCallum \& Tucker, 1991). An examination of the differences in error variances indicated that Item 2 (i.e., "Someone at work tells jokes about your ethnic group") had a larger error term for Hispanics (.66) than for Anglos (.27) and that Item 4 (i.e., "Someone at work excludes you from social interactions because of your ethnicity") had a larger error term for Anglos (.74) than for Hispanics (.05). Thus, these two items may have been measured with differential reliability in the two ethnic groups. Because the fits of the multisample models were reasonable until the addition of the equal error variance constraints, we were still relatively confident that the model would be equivalent for the two groups (MacCallum \& Tucker, 1991).

Combining all of the data from Hispanic and Anglo participants in our four samples resulted in 556 cases with complete data on all seven items $(\alpha=.79)$. The interitem correlation matrix, item means, and standard deviations for the combined sample are shown in Table 3. A confirmatory factor analysis conducted on the combined data suggested that the fit indexes for the two-factor model were reasonable. The goodness-of-fit index (GFI) was .95, the adjusted goodness-of-fit index (AGF) was .90, the comparative fit index (CFI) was .93, the normed fit index (NFI) was .92, the non-normed fit index (NNFI) was .89 , and the root mean square residual (RMSR) was .05. The chi-square value ( $d f=13$ ) was $103.60\left(\chi^{2} / d f\right.$ ratio: 7.97$)$. The parameter loadings for each

Table 2

Goodness of Fit of the Ethnic Harassment Experiences Scale for Hispanic and Anglo Groups

\begin{tabular}{lrrrrrrr}
\hline \multicolumn{1}{c}{ Hypothesis } & $x^{2}$ & df & $x^{2} / d f$ & GFI & CFI & NFI & NNFI \\
\hline Equal number of factors & 124.70 & 24 & 5.20 & .94 & .93 & .92 & .88 \\
Equal number of factors and item loadings & 145.95 & 31 & 4.70 & .93 & .92 & .90 & .89 \\
$\begin{array}{l}\text { Equal number of factors, item loadings, and factor } \\
\quad \text { correlations }\end{array}$ & 156.28 & 34 & 4.60 & .92 & .91 & .89 & .89 \\
$\begin{array}{l}\text { Equal number of factors, item loadings, factor } \\
\text { correlations, and measurement error }\end{array}$ & 425.13 & 41 & 10.37 & .81 & .73 & .71 & .73 \\
\hline
\end{tabular}

Note. GFI = goodness-of-fit index $;$ CFI $=$ comparative fit index $;$ NFI $=$ normed fit index; $N N F I=$ nonnormed fit index. 
Table 3

Interitem Correlation Matrix, Means, and Standard Deviations: Ethnic Harassment Experiences Scale

\begin{tabular}{|c|c|c|c|c|c|c|c|c|c|c|c|}
\hline \multirow[b]{2}{*}{ Item } & \multicolumn{2}{|c|}{ Anglo } & \multicolumn{2}{|c|}{ Hispanic } & \multirow[b]{2}{*}{1} & \multirow[b]{2}{*}{2} & \multirow[b]{2}{*}{3} & \multirow[b]{2}{*}{4} & \multirow[b]{2}{*}{5} & \multirow[b]{2}{*}{6} & \multirow[b]{2}{*}{7} \\
\hline & $M$ & $S D$ & $M$ & $S D$ & & & & & & & \\
\hline 1. Derogatory comments & 1.40 & 0.97 & 1.44 & 0.83 & - & .55 & .56 & .28 & .17 & .54 & .39 \\
\hline 2. Ethnic jokes & 1.44 & 0.97 & 1.82 & 1.07 & .75 & - & .49 & .19 & .15 & .37 & .27 \\
\hline 3. Ethnic slurs & 1.37 & 1.00 & 1.26 & 0.75 & .73 & .68 & - & .24 & .27 & .49 & .32 \\
\hline 4. Exclusion from social interactions & 1.41 & 1.06 & 1.10 & 0.59 & .35 & .27 & .34 & - & .70 & .30 & .54 \\
\hline 5. Failure to obtain information & 1.02 & 0.58 & 1.04 & 0.43 & .18 & .12 & .15 & .42 & - & .22 & .41 \\
\hline 6. Racist comments & 1.18 & 0.72 & 1.28 & 0.75 & .49 & .49 & .51 & .29 & .31 & - & .47 \\
\hline 7. Giving up ethnic identity & 1.10 & 0.66 & 1.21 & 0.78 & .33 & .28 & .27 & .30 & .36 & .44 & - \\
\hline
\end{tabular}

Note. Correlations below the diagonal are for Anglo respondents across the four combined samples $(n=207)$. Correlations above the diagonal are for Hispanic respondents across the four samples $(n=348)$. All correlations are significant at $p<.01$, except for the correlation between Items 2 and 5 among Anglo respondents, which was nonsignificant.

item were positive and significant (all $t \mathrm{~s}>12.9$ ), and the correlation between the two factors was .54. We compared the twofactor model with a one-factor model. The one-factor model did not fit the data as well. GFI, AGFI, NFI, NNFI, and CFI values were $.87, .72, .80, .69$, and .81 , respectively; the RMSR was .07 . The $\chi^{2} / d f$ ratio was 19.30 , and the chi-square value $(d f=14)$ was 270.22 .

The alpha reliability indexes for the two-factor EHE in all four samples were acceptable given the heterogeneous nature of some of the behaviors included in the scale and the relative sizes of the samples that completed all seven items. The reliabilities for the verbal ethnic harassment and exclusion factors, respectively, were .85 and .47 in Sample $1(n=117), .74$ and .49 in Sample $2(n=$ 43), .77 and .88 in Sample $3(n=97)$, and .82 and .63 in Sample 4 $(n=286)$

\section{Frequencies and Types of Ethnic Harassment Experiences}

Overall, a substantial percentage of respondents in each of our four samples indicated that they had been the target of at least one ethnically harassing behavior during the previous 24 months at work or on campus. Specifically, $52.2 \%$ of undergraduates in Sample 1, 67.4\% of the undergraduates in Sample 2, 40.2\% of school district employees, and $60.1 \%$ of graduate students had experienced at least one of the ethnically harassing behaviors.
Chi-square analyses conducted with all four samples indicated that there were no differences in the percentages of Anglos and Hispanics who reported at least one ethnically harassing experience. The ethnic harassment experiences of Anglo employees and students are particularly interesting, because there has been little empirical evidence of this phenomenon. We suspect that the relatively high percentages of Anglos reporting these types of experiences may be due to the nature of the contexts in which our four samples worked (i.e., Anglos were the numerical minority). One common complaint of Anglos in these contexts is that they feel excluded from workplace interactions when their coworkers speak Spanish, an experience they may interpret as ethnic harassment.

In all four samples, the most common ethnic harassment experience was being subjected to coworkers or peers telling jokes about one's ethnic group, whereas the second most common experience was hearing derogatory comments about one's ethnic group (see Table 4). Except for Sample 3, the least common experience in all samples was someone failing to give the respondent work-related information because of his or her ethnicity. In Sample 3, the least common experience was being excluded from interactions because of one's ethnic group membership.

For each sample, we computed scores based on participants' experiences of verbal harassment and exclusionary harassment due to their ethnic group membership. We examined the percentages of

Table 4

Ethnic Harassment Experiences Scale Items and Percentages of Respondents Reporting Each Item

\begin{tabular}{|c|c|c|c|c|}
\hline Item & $\begin{array}{c}\text { Undergraduate } \\
\text { Sample } 1 \\
(n=121)\end{array}$ & $\begin{array}{c}\text { Undergraduate } \\
\text { Sample } 2 \\
(n=46)\end{array}$ & $\begin{array}{c}\text { School district } \\
\text { employees } \\
(n=110)\end{array}$ & $\begin{array}{c}\text { Graduate } \\
\text { students } \\
(n=295)\end{array}$ \\
\hline Someone at work makes derogatory comments about your ethnicity & 27.3 & 42.2 & 23.8 & 35.6 \\
\hline Someone at work tells jokes about your ethnic group & 42.9 & 60.9 & 33.7 & 43.8 \\
\hline Someone at work uses ethnic slurs to describe you & 21.5 & 26.7 & 11.9 & 24,7 \\
\hline $\begin{array}{l}\text { Someone at work excludes you from social interactions during or after work because } \\
\text { of your ethnicity }\end{array}$ & 4.1 & 4.4 & 8.8 & 23.3 \\
\hline $\begin{array}{l}\text { Someone at work fails to give you information you need to do your job because of } \\
\text { your ethnicity }\end{array}$ & 2.5 & 4.4 & 9.8 & 9.0 \\
\hline $\begin{array}{l}\text { Someone at work makes racist comments (for example, says people of your ethnicity } \\
\text { aren't very smart or can't do the job) }\end{array}$ & 24.8 & 13.3 & 16.8 & 23.5 \\
\hline $\begin{array}{l}\text { Someone at work makes you feel as if you have to give up your ethnic identity to } \\
\text { get along at work }\end{array}$ & 6.6 & 8.7 & 10.0 & 18.8 \\
\hline
\end{tabular}




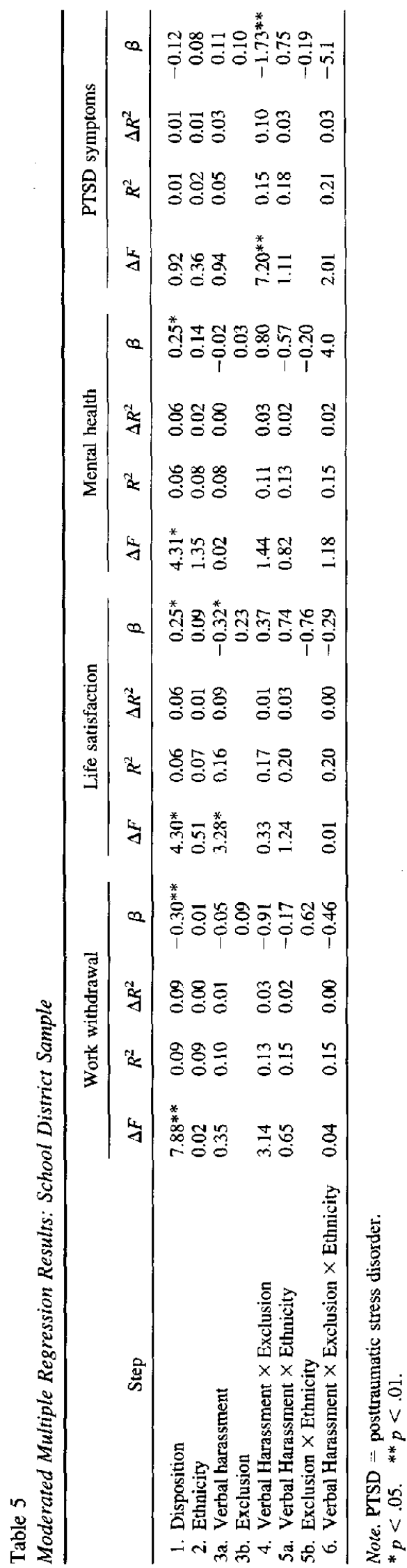

each sample experiencing each type of ethnic harassment or a combination of both types of ethnic harassment. In Samples 1, 2, and 3, the majority of ethnically harassed participants experienced verbal harassment without exclusionary harassment (i.e., between $27 \%$ and $54 \%$ ). In the graduate student sample, most harassed participants experienced both verbal harassment and exclusion $(28.7 \%)$, and a similar percentage $(26.6 \%)$ experienced verbal harassment only. Lower percentages of employees (7\%-11\%) in Samples 1-3 experienced both exclusion and verbal ethnic harassment, and the least common experience in all samples was exclusion due to ethnicity without accompanying verbal ethnic harassment (i.e., between $2 \%$ and $5 \%$ across the four samples).

\section{Correlates of Ethnic Harassment}

Analysis strategy. We examined the relationships between ethnic harassment experiences and their hypothesized correlates using the measures from Samples 3 and 4 . The means, standard deviations, and zero-order correlations among the variables are shown in Table 1. We performed a series of moderated multiple regression analyses to examine the hypothesized effects of verbal harassment, exclusion, and possible interactions of multiple types of harassment experiences and interactions of harassment with ethnicity. We proceeded with six steps of the regression analyses. Disposition was entered first, followed in order by ethnicity, verbal harassment and exclusion experiences, the interaction of the two types of harassment experiences, interactions of both verbal harassment and exclusion with ethnicity, and the three-way interaction among verbal harassment, exclusion, and ethnicity.

School district sample. Results of the moderated multiple regression using the correlates measured in Sample 3 (i.e., work withdrawal, life satisfaction, mental health, and posttraumatic stress symptoms) as dependent variables are shown in Table 5. Affective disposition was the only significant predictor of work withdrawal and mental health. For life satisfaction, even after disposition and ethnicity had been entered into the regression, there was a significant $R^{2}$ increase with the addition of verbal harassment and exclusion experiences. The significant beta weight

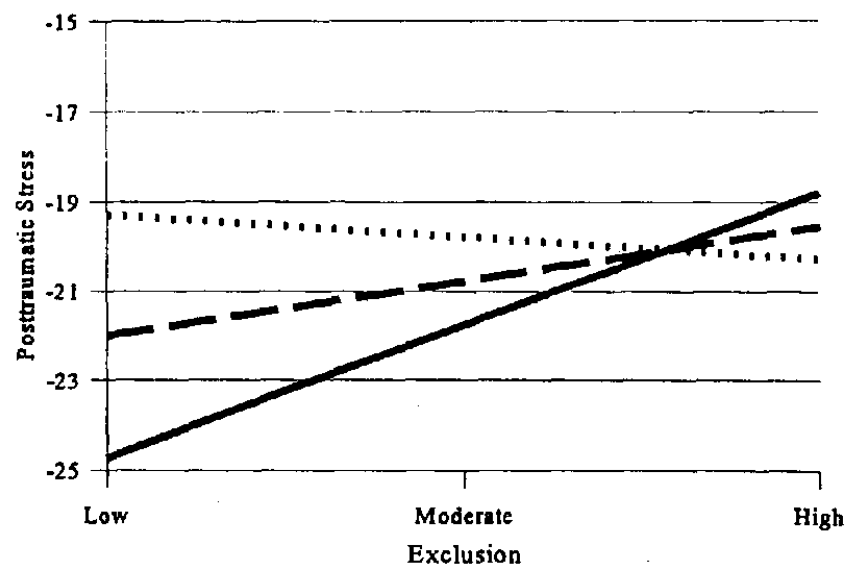

Figure 1. Interaction of verbal harassment and exclusion on posttraumatic stress of school district employees. Solid lines indicate low verbal harassment; dashed lines indicate moderate verbal harassment; dotted lines indicate high verbal harassment. 
for verbal harassment indicated that life satisfaction was lower for those reporting more incidents of verbal harassment. For posttraumatic stress symptoms, there was a significant interaction of verbal harassment and exclusion after disposition, ethnicity, and the main effects of the two types of harassment had been entered into the regression. Figure 1 indicates that, at lower levels of exclusion, those who experienced higher frequencies of verbal harassment reported more posttraumatic stress symptoms. However, as exclusion increased, those reporting lower levels of verbal harassment had more symptoms of posttraumatic stress than those with higher levels of verbal harassment.

Graduate student sample. As shown in Table 6, there was a significant interaction of verbal harassment and exclusion on both the life satisfaction and health conditions of graduate students. This interaction, similar to the effect in the school district sample, indicated that as exclusion experiences increased, those who reported low levels of verbal harassment reported lower life satisfaction (see Figure 2). Figure 2 shows a similar effect for health condition; higher scores indicate a better health condition. As exclusion increased, those who experienced low levels of verbal harassment reported worse health conditions than those who experienced higher levels of verbal harassment. There were no significant relations between ethnic harassment experiences and job attitudes, job behaviors, or health satisfaction. Table 6 shows the $F$ statistics and beta weights for job behaviors. For work withdrawal, there was a significant effect of ethricity, such that Hispanics reported higher levels of work withdrawal. There were also significant effects of disposition and ethnicity on job withdrawal such that individuals with more negative dispositions and Hispanics were more likely to report an intention to quit.

\section{Discussion}

Results from our four samples indicated that ethnic harassment was experienced by $40 \%$ to $67 \%$ of participants in diverse contexts. Our study provides one of the first empirical assessments of the types of ethnically harassing behaviors that people experience. We linked scores on the EHE to psychological well-being in two diverse settings, providing evidence that targets of such behaviors are also more likely to report lower levels of well-being. It is important to note that these relationships were evident even after covarying out respondents' affective disposition scores in both samples, indicating that the negative relationships between harassment and its correlates were not due to a tendency to experience innocuous events as negative.

In addition, we found evidence of differential effects of ethnic harassment based on experiences of exclusion and verbal harassment. We found a consistent pattern of interactions in both Samples 3 and 4 such that targets of high levels of exclusion and low levels of verbal harassment reported more negative correlates than those who experienced high levels of both exclusion and verbal harassment. We suggest that experiencing exclusion without accompanying verbal harassment may result in confusion on the part of the target in terms of the attributions made about the interaction. The targets of exclusion may not necessarily know which of their status dimensions to attribute the exclusion to (i.e., race, gender, or age), and this ambiguity may result in extremely detrimental effects on their well-being. This argument is similar to that proposed by Crocker et al. (1998), who contended that attributional

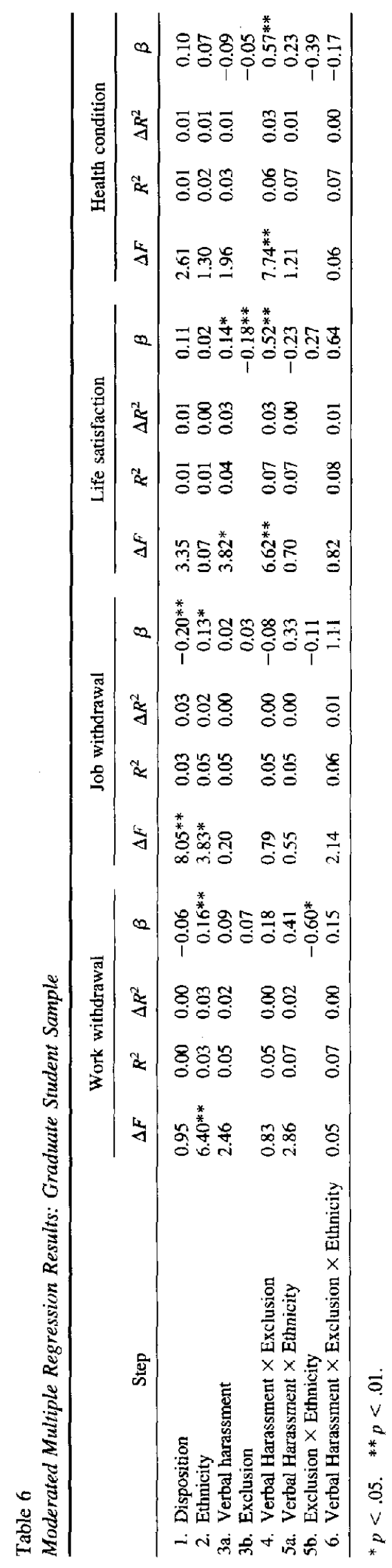



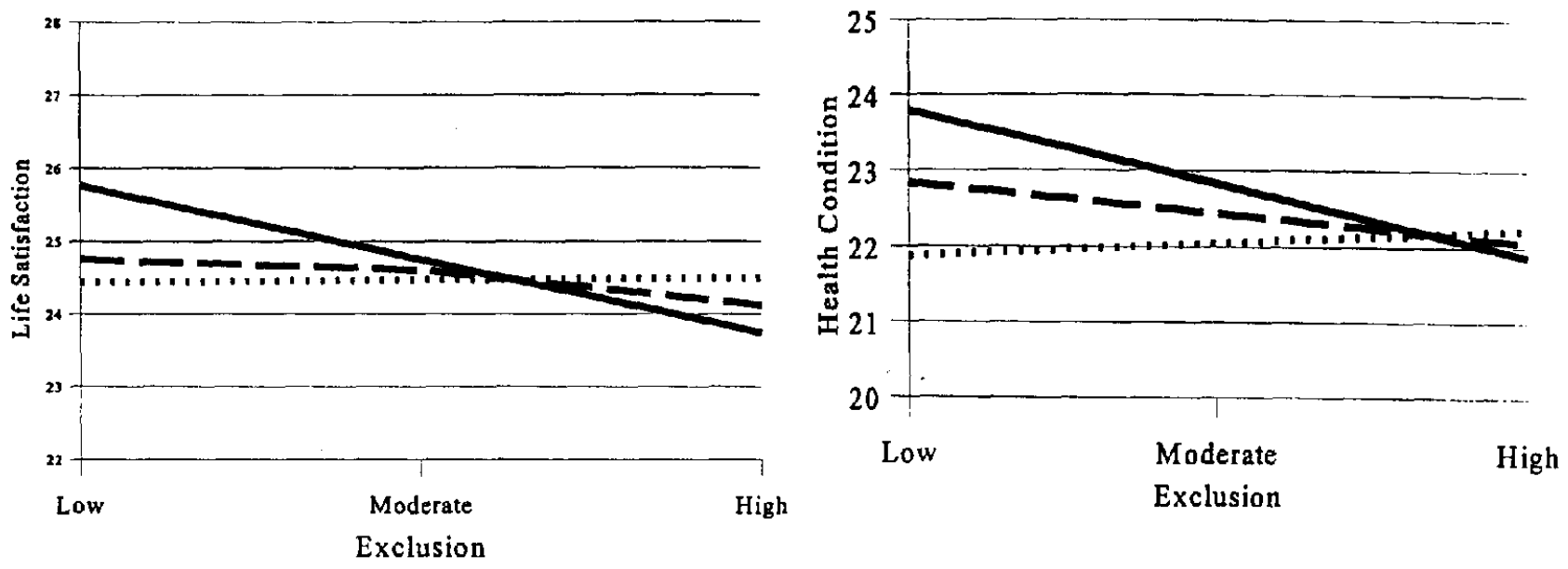

Figure 2. Interaction of verbal harassment and exclusion on life satisfaction and health conditions of graduate students. Solid lines indicate low verbal harassment; dashed lines indicate moderate verbal harassment; dotted lines indicate high verbal harassment.

ambiguity is detrimental to targets' self-esteem; that is, it would be less threatening to be sure that a rejection is the result of prejudice than to wonder whether it might have been due to prejudice. We propose that this represents a plausible explanation for the reactions of targets of frequent exclusion and frequent verbal harassment.

Although we did not find any interactions of harassment and ethnicity in our two samples, we see the need for future research to continue to examine the effects of ethnic harassment on different groups. Anglos in our samples reported rates of harassment experiences similar to those of Hispanics. This is consistent with a recent study by Ruggiero and Major (1998), who found that high-status participants (e.g., men and Whites) were more likely to attribute a negative outcome to discrimination. They proposed that members of high-status groups are vigilant in labeling discrimination relative to members of low-status groups, who may find the experience (and acknowledgment) of discrimination more threatening. We cannot ascertain whether Anglos overreported and Hispanics underreported harassment, as implied by Ruggiero and Major, or whether our results were due to the ethnic composition of the workplace. Because the majority of previous research has examined differences between Blacks and Whites, we view these findings as an intriguing extension of research on racial-ethnic experiences in the workplace.

In summary, our study represents one of the first attempts to measure the nature of harassment that people experience as a result of their ethnicity, along with the correlates of such experiences. Ethnically harassing experiences were related to scores on previously validated, psychometrically sound measures of correlates. The two-factor EHE appears to be relatively equivalent for Hispanics and Anglos. Results from two of our samples indicated that harassment experiences were negatively related to well-being (i.e., life satisfaction, posttraumatic stress, and health condition), and there were interesting interactions of verbal harassment and exclusion on these correlates.

Our general approach was based on examining ethnic harassment and its correlates by referring to research on discrimination, sexual harassment, and job stress. We propose that this represents a general workplace model that may generalize to other types of ethnic conflict at work. Ethnic harassment may have serious implications for subsequent interethnic work-group interactions. We see the need for continued research into the nature of ethnic harassment experiences, including measurement of ethnic diversity within work groups, and further explication of the possible mechanisms guiding the differential effects of multiple types of ethnic harassment experiences.

\section{References}

Brodman, K. A., Erdman, J., Jr., Lorge, I., \& Wolff, H. G. (1949). The Comell Medical Index. Journal of the American Medical Association, 140. 530-534.

Cervantes, R. C. (1992). Occupational and economic stressors among immigrant and U.S.-bom Hispanics. In S. B. Knouse \& P. Rosenfeld (Eds.), Hispanics in the workplace (pp. 120-133). Newbury Park, CA: Sage.

Crocker, J., \& Major, B. (1994). Reactions to stigma: The moderating role of justifications. In M. P. Zanna \& J. M. Olson (Eds.), The psychology of prejudice: The Ontario Symposium (Vol. 7, pp. 289-314). Hillsdale, NJ: Erlbaum.

Crocker, J., Major, B., \& Steele, C. (1998). Social stigma. In D. T. Gilbert, S. T. Fiske, \& G. Lindzey (Eds.), The handbook of social psychology (4th ed., Vol. 2, pp. 504-553). Boston: McGraw-Hill.

Diener, E., Emmons, R. A., Larsen, R. J., \& Griffin, S. (1985). The Satisfaction with Life Scale. Joumal of Personality Assessment, 49, 71-75.

Drasgow, F., \& Kanfer, R. (1985). Equivalence of psychological measurement in heterogeneous populations. Journal of Applied Psychology, 70 662-680.

Feagin, J. (1991). The continuing significance of race: Anti-Black discrimination in public places. American Sociological Review, 56, 101-116.

Fitzgerald, L. F., Drasgow, F., Hulin, C. L., Gelfand, M. J., \& Magley, V. J. (1997). Antecedents and consequences of sexual harassment in organizations: A test of an integrated model. Journal of Applied Psychology, 82, 578-589.

Fitzgerald, L. F., Hulin, C. L., \& Drasgow, F. (1995). The antecedents and consequences of sexual harassment in organizations: An integrated model. In G. P. Keita \& J. J. Hurrell, Jr. (Eds.), Job stress in a changing workforce: Investigating gender, diversity, and family issues (pp. 5573). Washington, DC: American Psychological Association. 
Fitzgerald, L. F., Shullman, S. L., Bailey, N., Richards, M., Swecker, J., Gold, A., Ormerod, A. J., \& Weitzman, L. (1988). The incidence and dimensions of sexual harassment in academia and the workplace. Journal of Vocational Behavior, 32, 152-175.

Gaertner, S. L., \& Dovidio, J. F. (1986). The aversive form of racism. In J. F. Dovidio \& S. L. Gaertner (Eds.), Prejudice, discrimination, and racism (pp. 61-89). San Diego, CA: Academic Press.

Gutierres, S. E., Saenz, D. S., \& Green, B. L. (1994). Job stress and health outcomes among White and Hispanic employees: A test of the personenvironment fit model. In G. P. Keita \& J. J. Hurrell, Jr. (Eds.), Job stress in a changing workforce: Investigating gender, diversity, and family issues (pp. 107-125). Washington, DC: American Psychological Association.

Hanisch, K. A. (1996). An integrated framework for studying the outcomes of sexual harassment: Consequences for individuals and organizations. In B. A. Gutek, L. Larwood, A. Stromberg (Series Eds.), \& M. S. Stockdale (Vol. Ed.), Women and work: Vol. 5. Sexual harassment in the workplace: Perspectives, frontiers, and response strategies (pp. 174198). Thousand Oaks, CA: Suge.

Hanisch, K. A., \& Hulin, C. L. (1991). General attitudes and organizational withdrawal: An evaluation of a causal model. Journal of Vocational Behavior, 39, 110-128.

Harrick, E. J., \& Sullivan, G. M. (1995). Racial harassment: Case characteristics and employer responsibilities. Employee Responsibilities and Rights Journal, 8, 81-95.

Hobfoll, S. E. (1991). Traumatic stress: A theory based on rapid resource loss. Anxiety Research, 4, 187-197.

Hurtardo, S. (1992). The campus racial climate: Contexts of conflict. Journal of Higher Education, 63, 539-569.

James, K. (1994). Social identity, work stress, and minority workers' health. In G. P. Keita \& J. J. Hurrell, Jr. (Eds.), Job stress in a changing workforce: Investigating gender, diversity, and family issues (pp. 127146). Washington, DC: American Psychological Association.

James, K., \& Khoo, G. (1991). Identity-related influences on the success of minority workers in primarily nonminority organizations. Hispanic Journal of Behavioral Sciences, 13, 169-192.

James, K., Lovato, C., \& Khoo, G. (1994). Social identity correlates of minority workers' health. Academy of Management Journal, 37, 383-396.

James, S. A., LaCroix, A. Z., Kleinbaum, D. G., \& Strogatz, D. S. (1984). John Henryism and blood pressure differences among Black men II: The role of occupational stressors. Journal of Behavioral Medicine, 7, 259-275.

Jöreskog, K., \& Sörbom, D. (1996). LISREL 8: User's reference guide. Chicago: Scientific Software International.

Judge, T. A. (1990). Job satisfaction as a reflection of disposition: Investigating the relationships and its effect on employee adaptive behaviors. Unpublished doctoral dissertation, University of Illinois at UrbanaChampaign.

Kahn, R. L., \& Byosiere, P. (1992). Stress in organizations. In M. D. Dunnette \& L. M. Hough (Eds.), Handbook of industrial and organizational psychology (Vol. 3, pp. 571-650). Palo Alto, CA: Consulting Psycholugists Press.

Krieger, N., \& Sidney, S. (1996). Racial discrimination and blood pressure: The CARDIA study of young Black and White adults. American Journal of Public Health, 86, 1370-1378.
MacCallum, R. C., \& Tucker, L. R. (1991). Representing sources of error in the common-factor model: Implications for theory and practice. Psychological Bulletin, 109, 502-511.

Pak, W. A., Dion, K. L., \& Dion, K. K. (1991). Social-psychological correlates of experienced discrimination: Test of the double jeopardy hypothesis. Intemutional Joumal of Intercultural Relations, 15, 243-254.

Radhakrishnan, P., \& Hitlan, R. T. (1998). The validity of a context-specific racial discrimination scale. Manuscript in preparation.

Reid, L., \& Radhakrishnan, P. (1998). The relation between race, perceptions of race, and self-perceptions of academic competence. Unpublished manuscript.

Roznowski, M. (1989). An examination of the measurement properties of the Job Descriptive Index with experimental iterns. Journal of Applied Psychology, 74, 805-814.

Ruggiero, K. M., \& Major, B. N. (1998). Group status and attributions to discrimination: Are low- or high-status group members more likely to blame their failure on discrimination? Personatity and Social Psychology Bulletin, 24, 821-837.

Saunders, B. F., Arata, C. M., \& Kilpatrick, D. G. (1990). Development of a crime-related post-traumatic stress disorder scale for women within the Symptom Checklist-90-Revised. Joumal of Traumatic Stress, 3, 439-448.

Schneider, K. T. (1997, May). Employees' experiences of ethnic harassment, sexual harassment, and bystander stress. Paper presented at the annual conference of the Midwestern Psychological Association, Chicago, IL.

Schneider, K. T., Swan, S., \& Fitzgerald, L. F. (1997). Job-related and psychological effects of sexual harassment in the workplace: Empirical evidence from two organizations. Joumal of Applied Psychology, 82, 401-414.

Smith, A., \& Stewart, A. J. (1983). Approaches to studying racism and sexism in Black women's lives. Journal of Social Issues, 39(3), 1-15.

Smith, E. M. J. (1985). Ethnic minorities: Life stress, social support, and mental health issues. The Counseling Psychologist, 13, 537-579.

Smith, P. C., Kendall, L. M., \& Hulin, C. L. (1969). The measurement of satisfaction in work and retirement. Chicago: Rand McNally.

Steele, C. M., \& Aronson, J. (1995). Stereotype threat and the intellectual test performance of African Americans. Journal of Personality and Social Psychology, 69, 797-811.

Szymanski, A. (1976). Racism and sexism as functional substitutes in the labor market. Sociological Quarterly, 17, 65-73.

Thompson, V. (1996). Perceived experiences of racism as stressful life events. Community Mental Health Joumal, 32, 223-233.

Veit, C. T., \& Ware, J. E. (1983). The structure of psychological distress and well-being in general populations. Journal of Consulting and Clinical Psychology, 51, 730-742.

Watson, D., \& Pennebaker, J. W. (1989). Health complaints, stress, and distress: Exploring the central role of negative affectivity. Psychological Review, 96, 234-254.

Weitz, J. (1952). A neglected concept in the study of job satisfaction. Personnel Psychology, 5, 201-205.

Received July 30, 1998

Revision received February 1, 1999

Accepted February 8, 1999 